\title{
A bibliometric overview of the Journal of Business Research
}

\author{
Merigó, José M. ${ }^{\text {; }}$ Mas-Tur, Alicia ${ }^{\text {; }}$ Roig-Tierno, Norat ${ }^{c}$; Ribeiro-Soriano, Domingo ${ }^{b}$ \\ ${ }^{a}$ Department of Management Control and Information Systems, University of Chile, Chile; \\ ${ }^{\mathrm{b}}$ Department of Business Administration, University of Valencia, Spain; ${ }^{\mathrm{c}}$ ESIC Business \\ and Marketing School, Valencia, Spain.
}

\begin{abstract}
The Journal of Business Research is a leading international journal in business research dating back to 1973. This study analyzes all the publications in the journal since its creation by using a bibliometric approach. The objective is to provide a complete overview of the main factors that affect the journal. This analysis includes key issues such as the publication and citation structure of the journal, the most cited articles, and the leading authors, institutions, and countries in the journal. Unsurprisingly, the USA is the leading region in the journal although a considerable dispersion exists, especially during the last years when European and Asian universities are taking a more significant position.
\end{abstract}

Keywords: Business research; bibliometrics; Web of Science; journal analysis. 